\title{
E, finalmente, a COVID-19
}

Paulo Santos, ${ }^{1}$ Tiago Maricoto, ${ }^{1}$ Ana Rita Maria, ${ }^{1}$ Ana Luísa Neves ${ }^{1}$

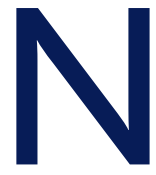
a ancestral luta pela sobrevivência, o Homo sapiens sapiens aprendeu ao longo da sua história que a vitória não estava na eliminação do agressor mas na capacidade de lidar com ele, adaptando-se e reequilibrando a seu favor a aparente desvantagem. Com a distância que os anos permitem, contam-se muito mais sucessos do que derrotas. Aprendemos a viver como seres multicelulares a partir da célula, como seres multiorgânicos a partir dos tecidos e como seres gregários a partir do indivíduo. Mais recentemente descobrimos que o conseguimos fazer também com outras espécies. Dos biliões de outros seres que connosco compõem o ecossistema terrestre temos alguns poucos que se assumem como predadores com quem não conseguimos estabelecer (ainda?) esta relação simbiótica e contra quem temos de recorrer a soluções tecnológicas que permitam o desequilíbrio a nosso favor. Entre eles estão alguns agentes patogénicos potencialmente geradores de doença e eventual morte.

No último ano e meio vivemos uma situação de crise pandémica motivada pela emergência do novo SARS-CoV-2. ${ }^{1}$ É um vírus da família dos coronavírus com especial tropismo para as vias respiratórias ainda que, como em muitos outros vírus, apresente um atingimento multissistémico. Como noutras doenças, o contacto inicial entre o agente e o hospedeiro é particularmente agressivo, tanto em termos de doença como da letalidade específica. Recordemo-nos da peste negra provocada pela Yersinia pestis, da tuberculose do Mycobacterium tuberculosis, da sífilis do Treponema pallidum, da gripe de 1918-19 por influenza A H1N1, da cólera por Vibrio cholerae, da varíola, etc. A atual situação da COVID-19 tem a característica de ser a primeira pandemia em contexto de globalização e de partilha universal de informação, com impactos imediatos e transfronteiriços. Vivemos num espaço global no qual os problemas de saúde pública se expandem rapidamente: o que acontece hoje no norte de Itália é, em poucos dias, um desafio que se estende de Lisboa a Hel-

1. Editor da Revista Portuguesa de Medicina Geral e Familiar. sínquia, seja no contexto social e político seja no contexto de saúde. Numa situação de emergência para a qual não houve preparação possível, a organização e a articulação das respostas foram naturalmente subótimas, sobressaindo algum individualismo sem um enquadramento global e contextualizador. Das lições a retirar emerge a necessidade de estabelecer estratégias claramente alinhadas com os objetivos de interesse, definidos e sustentados por evidência científica robusta, ao nível local, regional e nacional.

Passada a fase inicial da emergência, o conhecimento acumulado e a menor pressão sobre os serviços de saúde abriram a oportunidade de encontrar respostas mais adequadas. No entanto, manteve-se a aposta em soluções únicas, as chamadas silver bullet approaches, em vez de incorporar a complexidade do contexto multifatorial. Esta dificuldade é reconhecida globalmente na organização dos serviços de saúde e traduz uma fragilidade sistemática não resolvida. Num sistema onde vários intervenientes concorrem para o outputfinal é fundamental aceitar a sua participação ativa e incorporar as diferentes perspetivas na definição dos objetivos, dos processos e das estratégias (systems thinking). Em alternativa, o espírito da reforma dos cuidados de saúde primários propôs a implementação de um nível de decisão mais próximo dos reais problemas na autonomia organizativa, funcional e técnica das unidades como solução para a decisão hierarquizada do eixo piramidal então existente, mas não conseguiu resolver os problemas da centralização dos recursos, do modelo de contratualização e da subordinação hierárquica dos $\mathrm{ACeS}^{2}$ que, embrulhados em atitudes de pouco rigor e falta de transparência, condicionam significativamente a definição dos objetivos, o desenho das estratégias e a aplicação dos respetivos processos. Por outro lado, a enorme carga legislativa criada nesta matéria, incluindo os regulamentos e normas técnicas, não foi acompanhada da necessária educação da população. O público foi bombardeado com grandes quantidades de informação de várias fontes, sem garantir o suporte adequado para a ativação destes conhecimentos em atitudes e aptidões capazes de modelar o risco individual. ${ }^{3}$ 
Estamos a entrar numa nova etapa da infeção por SARS-CoV-2. Num sprint tecnológico conseguimos ter vacinas eficazes e seguras num tempo recorde, mesmo contra as novas estirpes que entretanto surgiram - $\mathrm{e}$ continuarão a surgir.-6 $\mathrm{Na}$ Europa, as autoridades inglesas foram as primeiras a assumir a transição das recomendações de restrição com base nas evolução da vacinação, numa altura em que os dados oficiais do final da semana $28 / 2021$ apresentam $68,3 \%$ da população acima dos 18 anos com vacinação completa contra os 52,5\% da União Europeia (59,6\% em Portugal). Na perspetiva de que iremos (con)viver com o vírus, passamos das contagens de casos e de mortos para uma abordagem de risco baseada na carga de doença e na capacidade de resiliência dos serviços de saúde, medida sobretudo nos internamentos hospitalares, onde gera um consumo significativo de recursos materiais e humanos. Ao nível do ambulatório, esta situação significa necessariamente um abrandamento da pressão e a possibilidade de voltarmos à acessibilidade e ao contexto de exercício clínico que nos caracteriza e com que nos identificamos.

\section{REFERÊNCIAS BIBLIOGRÁFICAS}

1. Santos P, Maricoto T, Nogueira R, Hespanhol A. O médico de família e o Covid-19 [Family doctor and Covid-19]. Rev Port Med Geral Fam. 2020;36(2):100-2. Portuguese

2. Santos I, Santos P, Ramos V, Envia G, Monteiro J. Resposta à Covid-19: o que foi feito e o que há para fazer. Gestão Hospitalar. 2020;(21):249.

3. Silva MJ, Santos P. The impact of health literacy on knowledge and attitudes towards preventive strategies against COVID-19: a cross-sectional study. Int J Environ Res Public Health. 2021;18(10):5421.

4. Polack FP, Thomas SJ, Kitchin N, Absalon J, Gurtman A, Lockhart S, et al. Safety and efficacy of the BNT162b2 mRNA Covid-19 vaccine. N Engl J Med. 2020;383(27):2603-15.

5. Baden LR, El Sahly HM, Essink B, Kotloff K, Frey S, Novak R, et al. Efficacy and safety of the mRNA-1273 SARS-CoV-2 vaccine. N Engl J Med. 2021;384(5):403-16.

6. Voysey M, Clemens SA, Madhi SA, Weckx LY, Folegatti PM, Aley PK, et al. Safety and efficacy of the ChAdOx $1 \mathrm{nCoV}-19$ vaccine (AZD1222) against SARS-CoV-2: an interim analysis of four randomised controlled trials in Brazil, South Africa, and the UK. Lancet. 2021;397(10269): 99-111.

\section{ENDEREÇO PARA CORRESPONDÊNCIA}

E-mail: psantosdr@med.up.pt

https://orcid.org/0000-0002-2362-5527 